\title{
Design on Direct Crushing Garbage in the Garbage Dump Truck: A Case Study for Denpasar City, Bali, Indonesia
}

\author{
I Ketut Adi Atmika, I D. G. Ary Subagia, and Tjokorda Gde Tirta Nindhia
}

\begin{abstract}
In transporting of garbage, a phenomenon that often occurs is spilled garbage on the street. Aside from cause traffic, congestion and air pollution pose a unpleasant odor to the environment, either directly or indirectly have an impact also on public health. This study examines and assesses the performance of traction and vehicle stability performance of trucking garbage crusher which is integrated with screw operated at various conditions / field operations. The analysis is focused on analyzing the behavior of the vehicle rolling. Analysis of vehicle traction performance model is able to overcome various obstacles, with a capable pass climbs up to 24 degrees, with the traction needed up to $52000 \mathrm{~N}$ and the minimum prediction engine power of $142 \mathrm{hp}$. On the road conditions turn up the speed of $60 \mathrm{~km} / \mathrm{h}$, the magnitude of the normal force on each wheel is still positive, then the vehicle is still safe for the rolling conditions.
\end{abstract}

Index Terms-Screw crusher, traction performance, behavioral directions, Rolling analysis.

\section{INTRODUCTION}

Garbage often interferes with comfort because it smells unpleasant and unfavorable views. Increasing number of garbage today lead processing becomes imperfect and sometimes not transported by the local department because too many industries and households. This problem is experienced by one of the provincial capital of Bali, Denpasar. Denpasar city generated garbage every day at this time of $2200 \mathrm{~m}^{3}$ to $2500 \mathrm{~m}^{3}$. The Department is responsible for the cleanliness of the environment, namely Denpasar city and Sanitation Department (DKP), DKP currently has a vehicle of 96 units with a number of feasibility level as garbage that can be said is inadequate, especially in terms of comfort and performance of traction and rolling behavior.

In transporting garbage, a phenomenon that often occurs is spilled garbage on the street. Aside from the cause traffic, congestion and air pollution which is pose a less pleasant odor to the environment in its path, either directly or indirectly have an impact also on public health. The phenomenon of garbage transport vehicle in Denpasar, Bali, Indonesia shown in Fig. 1.

The purpose of this study is to test and assess the performance of traction, stability and security performance models of vehicles carrying garbage. While the final phase of

Manuscript received June 16, 2014; revised August 30, 2014. This work was supported by Directorate General Higher Education of The Republic of Indonesia under scheme of Ungulan perguruan tinggi under Conrack number 103.8/UN 14.2/PNL.01.03.00/2004.

The authors are with the Department of Mechanical Engineering, Engineering faulty, Udayana University, Denpasar, Indonesia (e-mail: tutadi2001@yahoo.com, arsubmt@gmail.com,nindhia@yahoo.com). the overall activities of the research design and mechanization of garbage transport vehicle integration crasher (screw crusher) is expected to generate a mechanism of transport vehicles and construction waste that meets the eligibility standards of operation. The design vehicles haul trucks garbage crusher is integrated with the screw shown in Fig. 2. Process on garbage transport vehicle started by including garbage organic into waste hopper to the system crusher step by step where in it there are system of sieve and receptacle water waste.

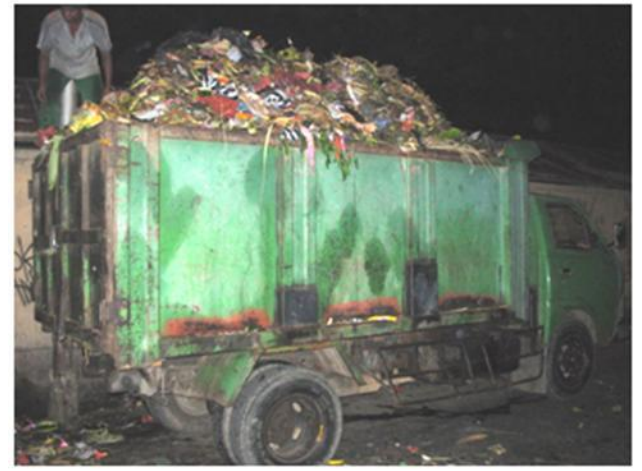

Fig. 1. The phenomenon of garbage transport vehicle in Denpasar, Bali, Indonesia. Spilled garbage on the street is often occurs.

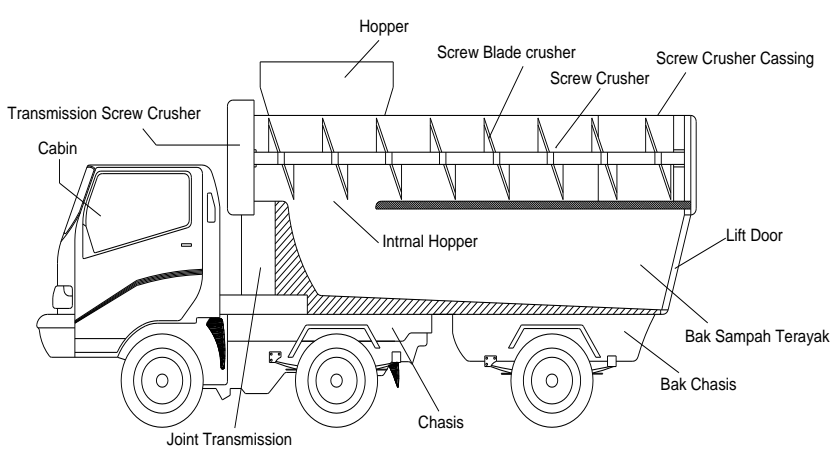

Fig. 2. The prototype design garbage transport vehicle integrated crusher.

Some researchers have expressed motor vehicle other than have a definite ability to transport goods and people also should have quality in terms of stability and comfort and safety.

Research entitled advance Automotive Control System in the Future to develop a concept vehicle directional stability control which is essentially still based on braking and torque control [1]. The research has developed a 4-wheel drive system (4WS) that can have multiple parameters to improve directional stability and the ability to turn the vehicle [2], [3].

Research and study with the topic design of mechanical hidroulis Semilock Brake System with Load Sensing Proportioning Valve combination and Membranes to develop 
the concept of semi-lock brakes which can improve the ability to turn the vehicle and directional stability of the vehicle [4].

The research have developed a control system of the vehicle directional stability by providing or reduction of force on the brake wheel by utilizing ABS, and controlling the torque with a CVT and integrated harness system with 4-wheel steering [5] and study with Smart Handling with Gyroscopic Component [6].

From predecessor automotive technology development focuses just only on the issue of security, stability, and comfort. Furthermore, to be able to answer the problem of transporting garbage transportation technologies, in this research will be developed prototype vehicle with the integrated trash integrated with crasher (screw crusher), which begins with the testing and assessment of the performance of traction and roll behavior of the vehicle's performance.

\section{METHODE}

Traction characteristics on motor vehicles principally covers the vehicle's ability to accelerate, and overcome the obstacles that occur, including rolling resistance (rolling resistance), climb obstacles, as well as aerodynamic resistance. From the concept of inertia force, traction and derived equations written in general [7]:

$$
F=R_{a}+R_{r}+R_{d}+R_{g}+\frac{W}{g} . a
$$

$$
\begin{aligned}
& F=\text { total traction force required }(\mathrm{N}) \\
& R_{a}=\text { aerodynamic resistance }(\mathrm{N}) \\
& R_{r}=\text { Rolling resistance }(\mathrm{N}) \\
& R_{d}=\text { barriers for pulling loads }(\mathrm{N}) \\
& R_{g}=\text { barriers ramp }(\mathrm{N}) \\
& W=\text { total vehicle weight }(\mathrm{N}) \\
& a=\text { acceleration of the vehicle }\left(\mathrm{m} / \mathrm{dt}^{2}\right)
\end{aligned}
$$

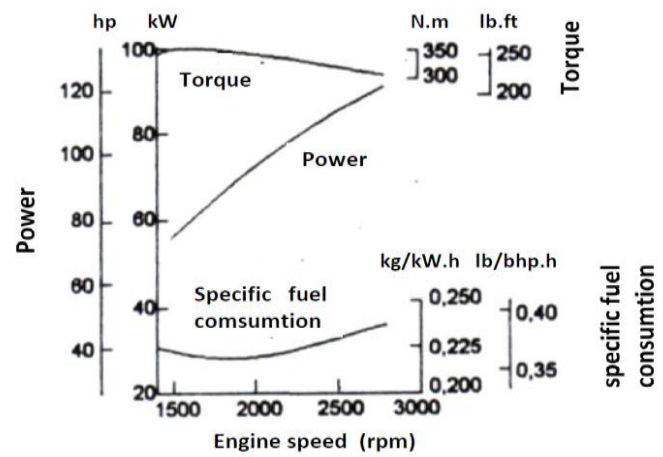

Fig. 3. Graph of Power-Torque Characteristics vehicles in general for each speed [8].

For application in motor vehicles, the characteristics of an ideal power source for propulsion is generated constant power at all speed levels. With the availability of constant power, at low speeds will be available torque is large enough, will be used to generate enough traction on the wheels to accelerate the vehicle. With increasing speed, engine torque will decrease hyperbolic. This is in accordance with the needs traction on vehicles, where the speed is high enough, no longer needs huge traction. Power-Torque Characteristics
Graph vehicles in general for each speed (rpm) is shown in Fig. 3.

When a drive train system is characterized by the parameters of the drive train system efficiency $\eta_{t}$ and the reduction gear ratio $i$, the traction on the drive wheels can be formulated [7]:

$$
F_{k}=\frac{M_{e}(v) \cdot i_{k} \cdot i_{d}}{r} \mathrm{~h}_{t}
$$

$F_{k}=$ traction force on the k-th level $(\mathrm{N})$

$M_{e}=$ engine torque to speed $v(\mathrm{Nm})$

$R=$ the radius of the driving wheels (m)

$i_{k}=$. gear ratio of the $\mathrm{k}$-th

$i_{d}=$ Differential gear ratio

The study begins with a literature review on previous studies and supporting various theories relating to the traction vehicle. Then determine the type of vehicle to be tested, followed by the collection of data necessary vehicle models. The initial step is to test the power-torque characteristics of the engine model vehicles. Then do the analysis of the traction capabilities are able to produce models of vehicle transmission system in various conditions / field operations, also analyzed the behavior of the direction (analysis bolsters) vehicle models.

\section{RESULT AND DICUSSION}

Characteristics of power - engine torque model vehicle is shown in Fig. 4.



Fig. 4. Characteristics of power - engine torque model vehicle.

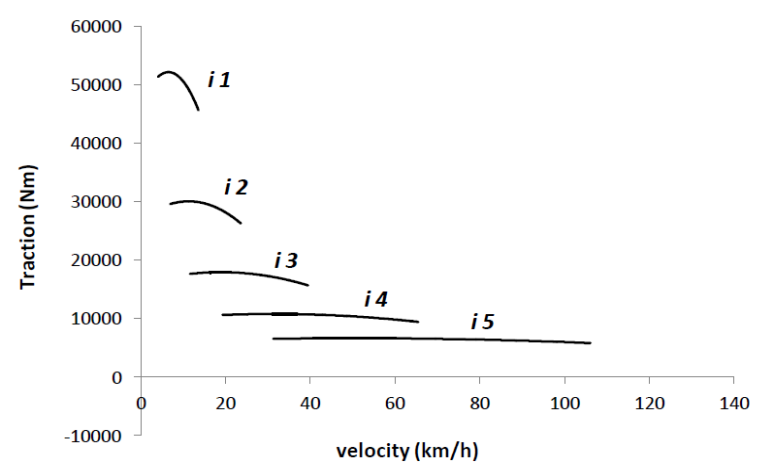

Fig. 5. Characteristics of traction Vehicle model.

Calculation and Analysis of Performance Traction (at engine speed $1500 \mathrm{rpm}$ ) vehicle speed (V) shown in Fig. 
5-Fig. 7, characteristics normal force shown in Table I, and skid condition on type of road and some variation of speed shown from Table II up to Table VIII. Road type taken for example calculation is the wet concrete, wet asphalt and wet land. While the variation of the simulated vehicle speed is 40 $\mathrm{km} / \mathrm{h}, 50 \mathrm{~km} / \mathrm{h}$ and $60 \mathrm{~km} / \mathrm{h}$.

Curve achieved, as shown in Fig. 5, almost obtain ideal condition where the higher of speed the lower of traction needed. The maximum traction $(5200 \mathrm{Nm})$ achieved can through any road conditions that exist in the city of Denpasar, so based on vehicle traction performance it is feasible for use [7].

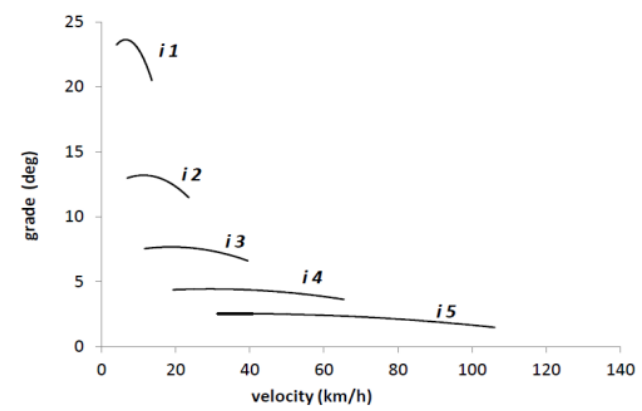

Fig. 6. Characteristics of grade.

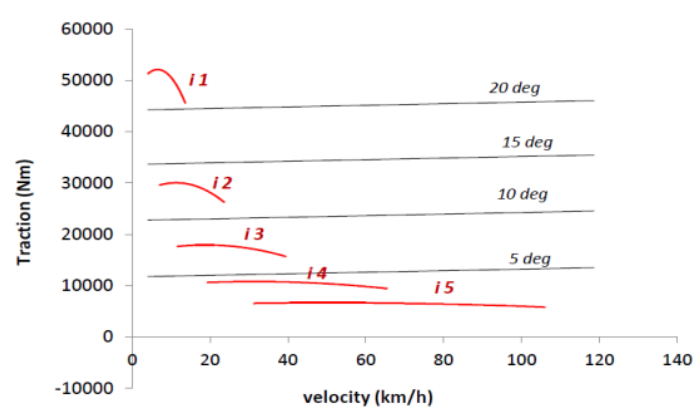

Fig. 7. Characteristics of traction and grade.

TABLE I: CHARASTERISTICS NORMAL FORCE

\begin{tabular}{|c|l|l|c|c|}
\hline \multirow{2}{*}{$\begin{array}{c}\text { Steer angle } \\
(\mathrm{deg})\end{array}$} & \multirow{2}{*}{$\begin{array}{c}\text { fzf } \\
(\mathrm{N})\end{array}$} & \multirow{2}{*}{$\begin{array}{c}\text { fzr } \\
(\mathrm{N})\end{array}$} & \multicolumn{2}{|c|}{ rolling } \\
\hline 4.5 & 9236.5 & 11140 & no & no \\
\hline 5 & 9240 & 11145 & no & no \\
\hline 5.5 & 9238.5 & 11140.5 & no & no \\
\hline 6 & 9237.5 & 11139 & no & no \\
\hline 6.5 & 9241 & 11137 & no & no \\
\hline 7 & 9240 & 11140 & no & no \\
\hline 7.5 & 9243.5 & 11138 & no & no \\
\hline 8 & 9242.5 & 11136 & no & no \\
\hline
\end{tabular}

TABLE II: CHARASTERISTICS OF SIDE FORCE AT 40 KM/H ON WET LAND

\begin{tabular}{|c|c|c|c|c|c|c|}
\hline $\begin{array}{c}\text { Steer } \\
\text { angle }\end{array}$ & Fyf & Fyr & Fycf & Fycr & Skid condition \\
\hline deg & $\mathrm{N}$ & $\mathrm{N}$ & $\mathrm{N}$ & $\mathrm{N}$ & front & rear \\
\hline 4.5 & 905.6 & 3426 & 5080.5 & 6128 & No skid & No skid \\
\hline 5 & 1172.5 & 3811.5 & 5080.5 & 6128 & No skid & No skid \\
\hline 5.5 & 1433.5 & 4188.5 & 5081.5 & 6127 & No skid & No skid \\
\hline 6 & 1687 & 4555.5 & 5081.5 & 6127 & No skid & No skid \\
\hline 6.5 & 1933 & 4912 & 5082 & 6127 & No skid & No skid \\
\hline 7 & 2171 & 5256.5 & 5082.5 & 6126 & No skid & No skid \\
\hline 7.5 & 2399.5 & 5588 & 5082.5 & 6126 & No skid & No skid \\
\hline 8 & 2618 & 5906 & 5084.5 & 6126 & No skid & No skid \\
\hline
\end{tabular}

The vehicle is able to overcome the grade resistance of 24 degree, as shown in Fig. 6, so it can operate well due to the maximum grade resistance in Denpasar City is 20 degree [7], [8]. From Fig. 7, it is shown the grade resistance ability of vehicle at various transmission levels. It can be seen that grade resistance of 5 and 10 degree can be overcame by use of transmission ratio of 3 and 2 respectively. Meanwhile, grade resistance of 15 and 20 degree can be through by using transmission ratio of 1 [7].

All of the front and rear normal forces have positive value for all of steer angle, as shown in Table I, so that the condition does not affect vehicle rolled [5], [8].

TABLE III: CHARASTERISTICS OF SIDE FORCE AT 50 KM/H ON WET CONCRETE

\begin{tabular}{|c|c|c|c|c|c|c|}
\hline $\begin{array}{c}\text { Steer } \\
\text { angle }\end{array}$ & Fyf & Fyr & Fycf & Fycr & \multicolumn{2}{|c|}{ Skid condition } \\
\hline deg & $\mathrm{N}$ & $\mathrm{N}$ & $\mathrm{N}$ & $\mathrm{N}$ & front & rear \\
\hline 4.5 & 2271.5 & 5637 & 7391.5 & 8906.5 & No skid & No skid \\
\hline 5 & 2606 & 6129 & 7395 & 8904 & No skid & No skid \\
\hline 5.5 & 2929.5 & 6605.5 & 7398.5 & 8901 & No skid & No skid \\
\hline 6 & 3240 & 7064.5 & 7397 & 8903.5 & No skid & No skid \\
\hline 6.5 & 3536.5 & 7505 & 7400.5 & 8901 & No skid & No skid \\
\hline 7 & 3818.5 & 7926 & 7399 & 8898 & No skid & No skid \\
\hline 7.5 & 4086 & 8325.5 & 7402.5 & 8895.5 & No skid & No skid \\
\hline 8 & 4338 & 8704 & 7482.5 & 8897.5 & No skid & No skid \\
\hline
\end{tabular}

Table II and Table III shows the side force both front and rear happens to the vehicle is still smaller than the side force that is capable of being held by the wheel, so does not happen skid of all steer angle [8]. Table II shows the skid condition at a speed of $40 \mathrm{~km} / \mathrm{h}$ which is operated on a wet land, while Table III shows the skid condition at $50 \mathrm{~km} / \mathrm{h}$ on wet concrete road.

From the Table IV, in the steer angle of $7 \mathrm{deg}$, rear side force that occurs in a vehicle is greater than the side force that is capable of being held next to the wheel, the skid occurs on the vehicle. So on wet asphalt road at speed of $50 \mathrm{~km} / \mathrm{h}$, the vehicle will slip to the right side when turn the left [8].

TABLE IV: CHARASTERISTICS OF SIDE FORCE AT $50 \mathrm{KM} / \mathrm{H}$ ON WET ASPHALT

\begin{tabular}{|c|c|c|c|c|c|c|}
\hline $\begin{array}{c}\text { Steer } \\
\text { angle }\end{array}$ & Fyf & Fyr & Fycf & Fycr & \multicolumn{2}{|c|}{ Skid condition } \\
\hline deg & $\mathrm{N}$ & $\mathrm{N}$ & $\mathrm{N}$ & $\mathrm{N}$ & front & rear \\
\hline 4.5 & 2271.5 & 5637 & 6469.5 & 7792 & No skid & No skid \\
\hline 5 & 2606 & 6129 & 6470.5 & 7790.5 & No skid & No skid \\
\hline 5.5 & 2929.5 & $\begin{array}{c}6605 \\
5\end{array}$ & 6471.5 & 7790 & No skid & No skid \\
\hline 6 & 3240 & $\begin{array}{c}7064 \\
5\end{array}$ & 6473 & 7789 & No skid & No skid \\
\hline 6.5 & 3536.5 & 7505 & 6474 & 7787.5 & No skid & No skid \\
\hline 7 & 3818.5 & 7926 & 6474.5 & 7786.5 & No skid & Skid \\
\hline
\end{tabular}

TABLE V: CHARASTERISTICS OF SIDE FORCE AT $50 \mathrm{KM} / \mathrm{H}$ ON WET LAND

\begin{tabular}{|c|c|c|c|c|c|c|}
\hline $\begin{array}{c}\text { Steer } \\
\text { angle }\end{array}$ & Fyf & Fyr & Fycf & Fycr & \multicolumn{2}{|c|}{ Skid condition } \\
\hline deg & $\mathrm{N}$ & $\mathrm{N}$ & $\mathrm{N}$ & $\mathrm{N}$ & front & rear \\
\hline 4.5 & 2271.5 & 5637 & 5083 & $\begin{array}{c}6122 \\
5\end{array}$ & No skid & No skid \\
\hline 5 & 2606 & 6129 & $\begin{array}{c}5078 \\
5\end{array}$ & 6127 & No skid & Skid \\
\hline 5.5 & 2929 & 6605 & 6471 & 6444 & No skid & Skid \\
\hline 6 & 3240 & 7060 & 6473 & 6965 & No skid & Skid \\
\hline
\end{tabular}


TABLE VI: CHARASTERISTICS OF SIDE FORCE AT 60 KM/H ON WET

\begin{tabular}{|c|c|c|c|c|c|c|}
\hline $\begin{array}{c}\text { Steer } \\
\text { angle }\end{array}$ & Fyf & Fyr & Fycf & Fycr & \multicolumn{2}{|c|}{ Skid condition } \\
\hline deg & $\mathrm{N}$ & $\mathrm{N}$ & $\mathrm{N}$ & $\mathrm{N}$ & front & rear \\
\hline 4.5 & 3720.2 & 8127.5 & 7400.5 & 8888.5 & No skid & No skid \\
\hline 5 & 4689.9 & 9697 & 7408 & 8888 & No skid & Skid \\
\hline 5.5 & 2955 & 6605.5 & 6471 & 6290 & No skid & Skid \\
\hline 6 & 3240 & 7064.5 & 6473 & 6589 & No skid & Skid \\
\hline
\end{tabular}

From the Table V and the Table VI, in the steer angle of 5 $\mathrm{deg}$, rear side force that occurs in a vehicle is greater than the side force that is capable of being held next to the wheel, the skid occurs on the vehicle. So on wet land road at speed of 50 $\mathrm{km} / \mathrm{h}$ and on wet concrete road at $60 \mathrm{~km} / \mathrm{h}$, the vehicle will slip to the left side when turn the right [8].

TABLE VII: CHARASTERISTICS OF SIDE FORCE AT 60 KM/H ON WET ASPHALT

\begin{tabular}{|c|c|c|c|c|c|c|}
\hline $\begin{array}{c}\text { Steer } \\
\text { angle }\end{array}$ & Fyf & Fyr & Fycf & Fycr & \multicolumn{2}{|c|}{ Skid condition } \\
\hline deg & $\mathrm{N}$ & $\mathrm{N}$ & $\mathrm{N}$ & $\mathrm{N}$ & front & rear \\
\hline 4.5 & 3720.2 & 8127.5 & 6477.5 & 7778 & No skid & Skid \\
\hline 5 & 4535 & 6765 & 6425 & 4772 & No skid & Skid \\
\hline 5.5 & 5350 & 6243 & 6425 & 3788 & No skid & Skid \\
\hline
\end{tabular}

TABLE VIII: CHARASTERISTICS OF SIDE FORCE AT 60 KM/H ON WET LAND

\begin{tabular}{|c|c|c|c|c|c|c|}
\hline $\begin{array}{c}\text { Steer } \\
\text { angle }\end{array}$ & Fyf & Fyr & Fycf & Fycr & \multicolumn{2}{|c|}{ Skid condition } \\
\hline deg & $\mathrm{N}$ & $\mathrm{N}$ & $\mathrm{N}$ & $\mathrm{N}$ & front & rear \\
\hline 4.5 & 3720.2 & 8127.5 & 5089.5 & 6111.5 & No skid & Skid \\
\hline 5 & 4467 & 7767.5 & 6055 & 4256.2 & No skid & Skid \\
\hline 5.5 & 5249 & 6243 & 6525 & 2786 & No skid & Skid \\
\hline
\end{tabular}

In the steer angle of $4.5 \mathrm{deg}$ is shown the Table VII and the Table VIII, rear side force that occurs in a vehicle is greater than the side force that is capable of being held next to the wheel, the skid occurs on the vehicle. So at speed of $60 \mathrm{~km} / \mathrm{h}$ on wet asphalt and wet concrete road, the vehicle will slip to the left side when turn the right [8].

Analysis of vehicle traction performance model is able to overcome various obstacles, with a capable pass climbs up to 24 degrees, with the traction needed up to $52000 \mathrm{Nm}$. While inclination of road on Denpasar city not equal to that. So, the minimum prediction engine power of $142 \mathrm{hp}$. On the road conditions turn up the speed of $60 \mathrm{~km} / \mathrm{h}$, the magnitude of the normal force on each wheel is still positive, then the vehicle is still safe for the rolling conditions [8].

Skiding analysis of vehicle model, at speed of $40 \mathrm{~km} / \mathrm{h}$ the vehicle is not skidding for any variation of steer angle and in any tipe of road, this is because the side-force capable of being held by each wheel. Next on the vehicle speed $50 \mathrm{~km} / \mathrm{h}$ on wet concrete road do not occur skid too. While on wet asphalt road type has occurred skid at angle steer of $7 \mathrm{deg}$, on a wet land occurred skid at steer angle of $5 \mathrm{deg}$, and on the wet asphalt road already skidding at steer angle $4.5 \mathrm{deg}$. From the analysis of the skid, the vehicle model will be safe if operated at a speed of $40 \mathrm{~km} / \mathrm{h} \mathrm{[7],} \mathrm{[8].}$

\section{CONCLUSSION}

Vehicle model is able to overcome various obstacles, with a capable pass climbs up to 24 degrees, with the traction needed up to $52000 \mathrm{~N}$ and the minimum prediction engine power of $142 \mathrm{hp}$. On the road conditions turn up the speed of $60 \mathrm{~km} / \mathrm{h}$, the magnitude of the normal force on each wheel is still positive, then the vehicle is still safe for the rolling conditions. From the analysis of the skid, the vehicle model will be safe if operated at a speed of $40 \mathrm{~km} / \mathrm{h}$.

\section{REFERENCES}

[1] C. Min, "Advance automotive control system in future," in Proc. International Pacific Conference 11 (IPC-11), November 2001.

[2] S. I. Nyoman and Y. Kaelani, "Dinamic characteristics of multi function four wheel steering system," presented at FISITA World Automotive Congress, June 2000.

[3] A. S. Pramono, D. Chandra, and P. Pandiatmi, "Smart system four whell steering (4 WS) berdasarkan kendali yaw rate," Jurnal Poros, vol. 2, 2007

[4] S. I Nyoman, P. A. Sigit, P. Made, and N. Didik, "Design elastic component to improve performance of ABS and directional stability of vehicle," in Proc. International Pacific Conference 11 (IPC-11), November 2001.

[5] ID. G. Ary Subagia and P. Agus Sigit, "Requirement for corner angle variation of rear wheel on four wheel steering system with controlled eunuch slip," Jurnal IPTEK, vol. 16, no. 1, February 2005.

[6] A. A. I Ketut, I D. G. Ary Subagia, S. I Nyoman, and P. Agus Sigit, "Simulation of Motorcycle smart handling with gyroscopic component," Jurnal IPTEK, vol. 20, no. 2, 2009.

[7] S. I Nyoman, Teknologi Otomotif - Teori dan Aplikasinya, Guna Widya, Surabaya, 2001.

[8] J. Y. Wong, Theory of Ground Vehicles, John Wiley \& Son, New York, 1978.

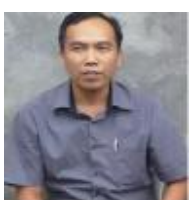

I K. A. Atmika is with the Department of Mechanical Engineering, Engineering Faulty, Udayana University, Denpasar, Indonesia. He was born in Negara, Bali, Indonesia on May 18, 1969, who received his master degree in mechanical engineering from ITS Surabaya, Indonesia in February 2004, with major field of study focused on design manufacturing engineering.

$\mathrm{He}$ participated in various national research collaboration such as ITS Surabaya (2004, 2007), Indonesia University (2006), etc.

His research interests cover subjects such as design and stability of automotive.

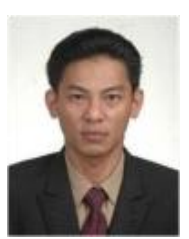

I D. G. Ary Subagia is with the Department of Mechanical Engineering, Engineering Faulty, Udayana University, Denpasar, Indonesia.

He was born in Singaraja, Bali, Indonesia on June 1, 1968. He received his doctor degree in mechanical engineering from Chonbuk National University-Korea Selatan, in August 2013 with major field of study focused on interply composite material engineering.

He participated in various international research collaboration such as the $1^{\text {st }}$ Korean Japan International Workshop on Energy and Reability (IWERe'2012), International Conference on Mechanical and Manufacturing Engineering (ICME) during December 17-19, 2013, Bangi, Putrajaya, Malaysia.

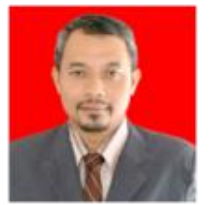

T. G. T. Nindhia is with the Department of Mechanical Engineering, Engineering Faulty, Udayana University, Denpasar, Indonesia.

He was born in Denpasar, Bali, Indonesia on January 16,1972 . He received his doctor degree in mechanica engineering from Gadjah Mada University (UGM) Yogyakarta, Indonesia in August 2003 with major field of study was material engineering.

He participated in various international research collaboration such as Muroran Institute of Technology Japan in 2004, Toyohashi University of Technology Japan in 2006, Leoben Mining University Austria from 2008 to 2009, Technical University of Vienna Austria in 2010 and recently Institute Chemical technology of Prague Czech Republic since 2012. 
